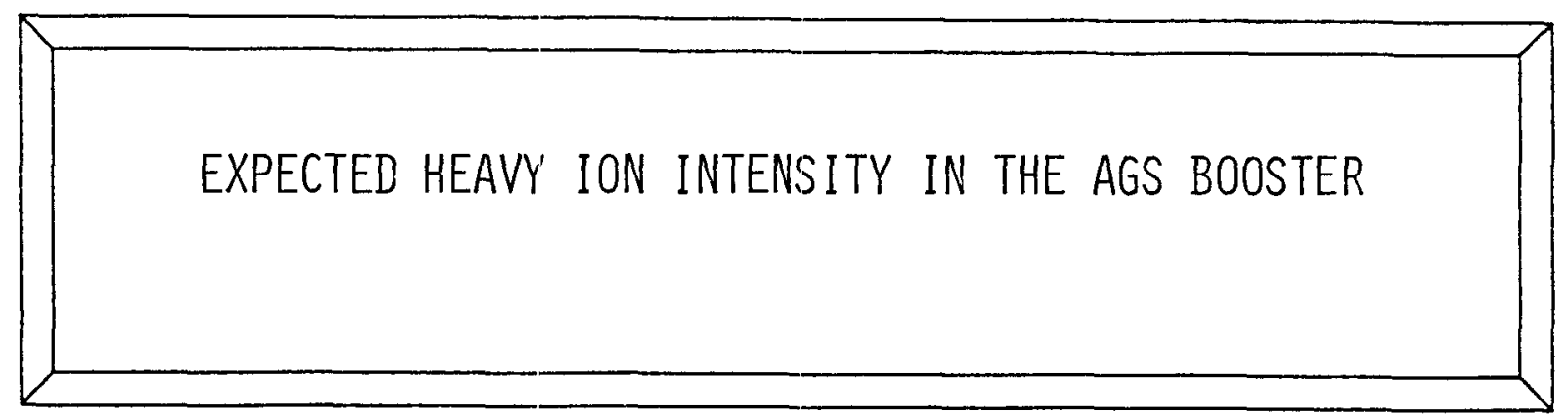

Booster Technical Note
No. 55

$Y, Y$, LEE

JULY 19, 1986

ACCELERATOR DEVELOPMENT DEPARTMENT

Brookhaven National Laboratory

Upton, N.Y. 11973 


\section{Y Y LEE}

In this note we try to estimate the expected intensity of heavy ions in the booster. A pulsed mode of operating the Tandem Van de Graaff developed at Brookhaven, showing that 300 micro-seconds long pulse of heavy ion could be accelerated without any adverse effects on the performance of the Van de Graaff. The Tandem output for the representative ion speces are given in the table I.

TABLE I

$\begin{array}{lccc}\text { IONS } & Q & \begin{array}{c}\text { T } \\ \text { MeV/amu }\end{array} & \begin{array}{c}\text { CURRENT } \\ \text { part-micro-amp }\end{array} \\ \text { CARBON } & 6 & 7.5 & 82 . \\ \text { SULFUR } & 14 & 4.7 & 20 . \\ \text { COPPER } & 21 & 2.9 & 11 . \\ \text { IODINE } & 29 & 1.65 & 6 . \\ \text { GOLD } & 33 & 1 . & 5 .\end{array}$

It is hard to estimate all the factors related to the intensity of the booster, however, following are list of the assumptions used and brief justification. 
i) The ion beams are injected into the booster stacking in the horizontal betatron phase space. The number of effective turns one can inject to the ring is complicated and hard to determine, however one can deduce from past experiences of other similar situation. When the AGS was injected with protons, experience shows that one can inject more than sixteen effective turns from the linac. The emmitance of the linac beam was about $5 \mathrm{~mm}-\mathrm{mr}$. The acceptance of the booster is somewhat larger than the AGS and the beam from the Tandem is about $1 \mathrm{mm-mr}$, a factor of five smaller than the linac. We expect to inject over twenty effective turns of the ions.

ii) There is another linitation to the intensity of the ion beams. namely the space charge limit. A conservative estimate is that one could stack at least to a space charge tune shift of .3 tune unit.

iii) RF capture efficiency is also hard to estimate. Since the injected beam from Tandem has virtually no energy spread, so called addiabatic capture of the beam takes too long(over $100 \mathrm{milli}$-seconds). Suggestion is made to capture in certain bunch size( $0.05 \mathrm{eV}$-sec/amu/bunch), and because we are bunching into much larger bucket than addiabatic bunch we expect veryhigh bunching efficiency for RF capture. Theoretically one can capture up to $98 \%$ of the particle even for addiabatic capture. Since we use larger bucket size, we assume better than $98 x$ capture efficiency.

iv) The final stripping efficiency is not well known, but a plausible guess is used except for gold which had been measured.

The table II shows the expected intensity for carbon, sulfur, copper, iodine, and gold lons. 
TABLE II

\begin{tabular}{|c|c|c|c|c|c|}
\hline & CARBIDN & SULFUR & COPPER & IODINE & GOLD \\
\hline $\mathrm{T}(\mathrm{MeV} / \mathrm{amu})$ & 7.5 & 4.7 & 2.9 & 1.65 & 1. \\
\hline $\mathrm{BETA}(V / \mathrm{C})$ & .1256 & .0997 & .0784 & .0592 & .0461 \\
\hline a & $6(6)$ & $14(16)$ & $21(29)$ & $29(53)$ & $33(79)$ \\
\hline I (PART - MICRO-AMP) & 82 & 20 & 11 & 6 & 5 \\
\hline $\begin{array}{l}N(a t \text { injection }) \\
20 \text { turns }(\times 109)\end{array}$ & 55 & 16.8 & 11.8 & 8.5 & $6.6^{*}$ \\
\hline RF CAPTURE EFFICIENCY & .98 & .98 & .98 & .98 & .98 \\
\hline$\underset{(\%)}{\text { VACUM SCATT. LOSS }}$ & $\sim 0$ & $\sim 0$ & $\approx .01$ & -.015 & $\sim .02$ \\
\hline $\begin{array}{c}N(a t \text { extraction) } \\
\times 109\end{array}$ & 54 & 16.5 & 11.4 & 8.2 & 6.3 \\
\hline $\begin{array}{c}\text { STRIPPING EFFICIENCY } \\
(\%)\end{array}$ & 100 & 290 & $>90$ & $>80$ & $\approx 50$ \\
\hline $\begin{array}{l}N(A G S) \\
\times 10^{9}\end{array}$ & 54 & $\sim 15$ & $\approx 10$ & 26.6 & $\sim 3.2$ \\
\hline
\end{tabular}

* Space charge tune shift limit of 0.3 